\title{
"Los argentinos descendemos de los barcos", pero... ¿de cuáles? Apuntes sobre la (in)visibilización de la negritud rioplatense en las prácticas artísticas contemporáneas
}

Andrea Díaz Mattei

“Ah! Maldito, maldito por mil veces Seas blanco sin fé, tu cruel memoria Sea eterno baldón para tu historia"

África mía! (1878), fragmento

Casildo Thompson, poeta afroporteño

Las narraciones mitificadas de ciertas realidades a menudo están plagadas de creencias, categorías y utopías que envuelven -en una dimensión simbólicael ideal de la ideología del poder dominante. Este es el caso que expondremos a continuación: la idea mitificada de la ascendencia "racial", blanca y europea, en la construcción de la identidad nacional en el Río de la Plata, así como de la argentinidad, y su cristalización en las estéticas visuales actuales en el arte contemporáneo.

Ya en la joven República de finales siglo XIX, en plena construcción del estado-nación argentino, se había fomentado un imaginario cultural identitario, el cual consistía en que no existían más "negros" argentinos y que sólo se trataba de un episodio -ya extinguido- de la colonia española (imaginario que por

\footnotetext{
${ }^{1}$ FORD 1899 [1878]: 1.
} 
cierto todavía hoy no se ha erradicado por completo). Pues, una clara voluntad política se había empeñado en difundir la idea, que luego se transformaría en creencia, del "blanqueamiento" y "europeización" de los argentinos. Tanto desde el discurso hegemónico de poder, desde las instituciones y sus políticas, como desde la educación y la intelectualidad en general, se negaban las raíces negras y autóctonas o de los pueblos originarios (como es políticamente correcto llamarlos en la actualidad), reservando o relegando estas raíces oscuras para ciertos folklorismos patrios e históricos.

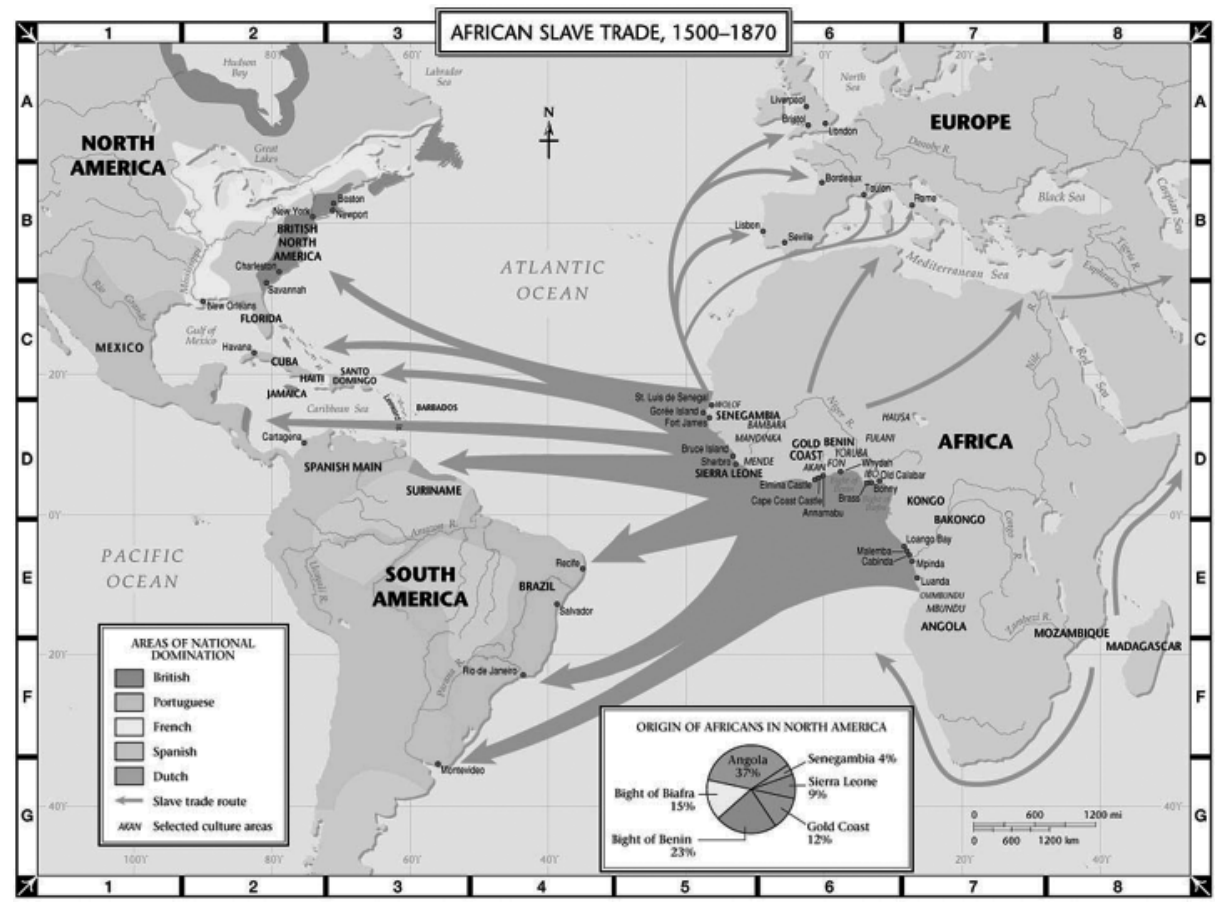

[Fig. 1. Pearson Education, Comercio de Esclavos Africanos, 1500-1870, 2003.]

El imaginario colectivo reza que la "identidad nacional" argentina se compone de un "crisol de razas", ${ }^{2}$ provenientes en su mayoría de la gran inmigración europea que tuvo lugar desde la segunda mitad del siglo XIX en adelante. Haciéndose eco de ello, algún famoso escritor mexicano ${ }^{3}$ afirmaba, con

${ }^{2}$ Según la RAE, crisol se define como un "recipiente hecho de material refractario, que se emplea para fundir alguna cosa" o como una "cavidad que en la parte inferior de los hornos sirve para recibir el metal fundido". Por lo tanto, el crisol de razas vendría a ser el contenedor de la fundición de todas las razas.

${ }^{3}$ Algunos se lo atribuyen a Carlos Fuentes, otros a Octavio Paz. 
ironía y juegos de palabras, que "mientras los mexicanos descendemos de los aztecas, los argentinos descienden de los barcos", revalidando esta creencia popular -al estilo de una frase hecha- que expresa una fuerte mitología arraigada sobre todo en la ciudad de Buenos Aires. A más inri, el escritor Jorge Luis Borges añadiría que "los argentinos son europeos nacidos en el exterior", blindando - de esta manera- el mito de la europeización, en detrimento de la idea (y del recuerdo) de que los barcos "negreros" esclavistas provenientes de África también recalaron en el puerto de Buenos Aires, y que, en consecuencia, la población africana esclavizada y su descendencia dejaron huella en la amalgama que compone nuestra identidad. De hecho, las estadísticas atestiguan que durante el siglo XIX el $30 \%$ de la población en Buenos Aires era negra o afrodescendiente (incrementándose este porcentaje en algunas provincias del interior del país, pues en el norte -donde había grandes plantaciones y minas de diversos minerales- podían llegar hasta un 40 o $50 \%)^{4}{ }^{4}$

Sin embargo, en este proceso secular de invisibilización, no sólo se involucraron los intelectuales y los libros de texto escolares, sino también las estadísticas. En efecto, respondiendo a este mandato, fue quitada del censo la pregunta sobre el origen racial, restituida recién en 2010 donde solo unas 150.000 personas reconocen su origen africano (un $0,4 \%$ sumando las categorías negro / negra y afrodescendiente), ${ }^{5}$ en las que además están incluidas las personas de origen africano que llegaron en los flujos migratorios de los últimos 10 años. Otro dato curioso es un estudio del Centro de Genética de la Facultad de Filosofía y Letras de la Universidad de Buenos Aires (perteneciente al Departamento de Antropología), que estimó que un 4,3\% de la población de Buenos Aires (incluyendo el conurbano) contiene marcadores genéticos africanos. Esto es unas 10 veces más de lo que las personas censadas reconocen.

\footnotetext{
${ }^{4}$ Para una mayor profundización véase: Piсотті 2000 y Piсотті 2001.

5 Datos del Cuestionario Censal: Afrodescendientes y Multiculturalismo según el Censo de Argentina 2010, véase: AfrodesCendientes 2010.

Datos Generales:

Población Total: 40.091.359

Extensión del País: 2.780 .400 km²

Densidad Poblacional: 14.4 habitantes por $\mathrm{km}^{2}$

Índice de Desarrollo Humano: Posición 45

Población Afrodescendiente, según Censo Poblacional 2010*: 149.493

*(Sumadas las categorías Negro / negra y Afrodescendiente)

$\%$ Población Afrodescendiente: $0.4 \%$.
} 


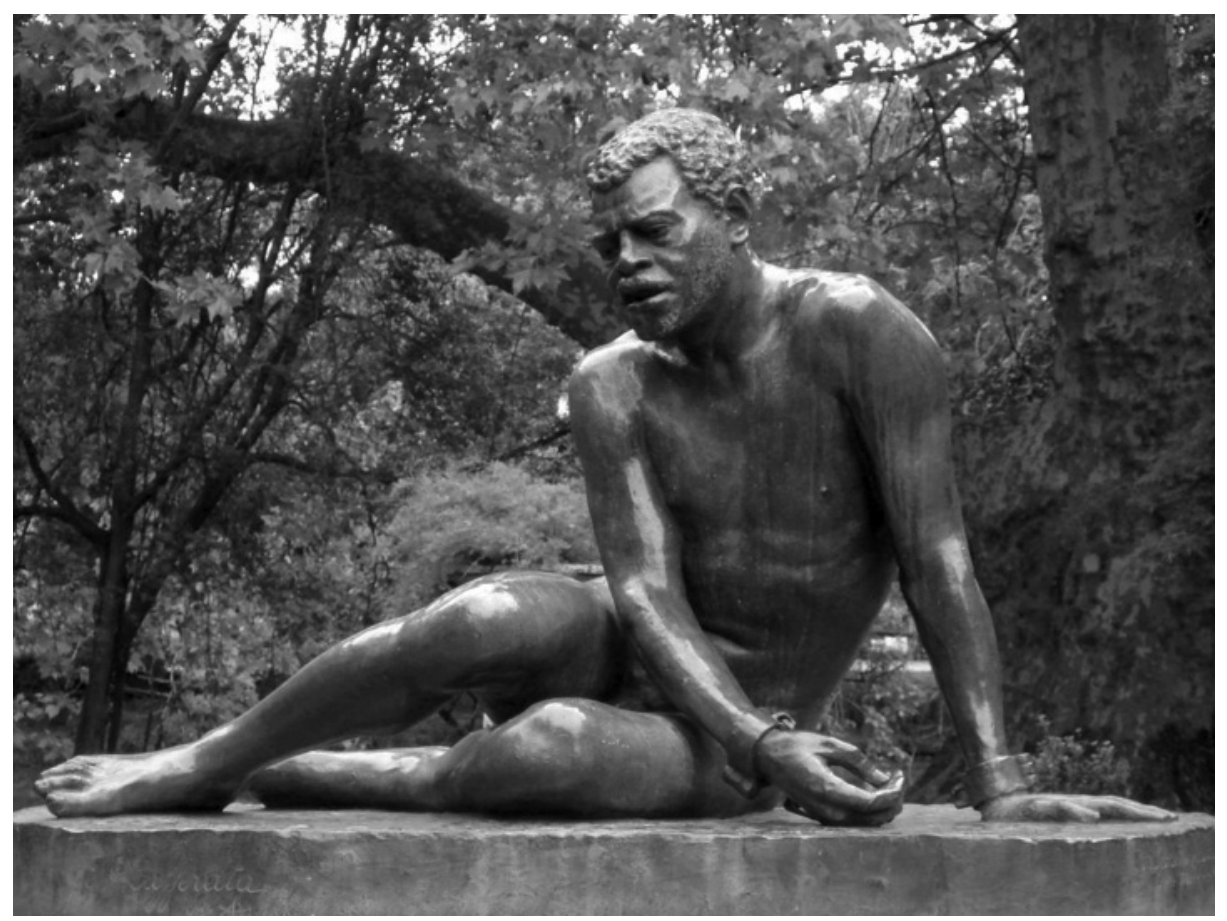

[Fig. 2. Francisco Cafferata, La esclavitud, 1881, bronce, Bosques de Palermo (Buenos Aires).]

Presentado el contexto, en este artículo no ahondaremos en datos históricos y/o estadísticos, ni en los muchos colectivos activistas y reivindicatorios que existen al respecto. Sin embargo, sí podemos afirmar que, a pesar de todos los estudios y datos que corroboran también un pasado negro argentino, afroascendiente (junto a las demás ascendencias, europeas y de los pueblos originarios), tanto el imaginario identitario cultural general como las estéticas y la cultura visual contemporáneas todavía parecen resistirse a dar este giro hacia el reconocimiento de la existencia de una porción de raíz africana en nuestra composición. Lo cierto es que pensadores como Aníbal Quijano, Walter Mignolo, Santiago Castro-Gómez o Boaventura de Sousa Santos describen muy bien este mecanismo de arraigo en lo que ellos llaman la matriz colonial del poder y su consecuente colonialidad epistémica o colonialidad del saber. Pues, si concebimos la colonización del saber o colonialidad epistémica como aquello más difícil de desalojar de nuestras subjetividades, ${ }^{6}$ podemos comprender que en Argentina y Latinoamérica - uno de aquellos "otros cercanos de Occidente"-todavía domine

${ }^{6}$ Véase: Quijano 1991: 11-20; Castro-Gómez, Grosfoguel 2007 y De Sousa Santos 2010 . 
un sistema de pensamiento occidental residual de la pasada colonización, acentuado en la colonialidad epistémica, del saber y del ser. Este pensamiento derivado, "colonializado" [acépteseme el neologismo], heredero del reduccionismo modernista europeo, conlleva en sí mismo una basa fundamental, la del racismo, tal como afirmara el poeta y político martiniqués Aimé Césaire en su Discurso sobre la negritud $(1987)^{7}$ y luego retomaran otros teóricos más adelante. Si el euroccidentalismo ${ }^{8}$ dominante comienza con la modernidad -en plena colonización de América Latina- y continúa más adelante con su vertiente humanista, no ha de sorprendernos la persistencia de su influencia como sistema de pensamiento vigente aún hoy en día, a pesar de los esfuerzos prácticos e intelectuales realizados para contrarrestarlo desde las décadas de los ' 60 y ' 70 . Un caso destacable es el del filósofo Enrique Dussel y su filosofía de la liberación ${ }^{9}$, el cual incitaba a deshacernos de esta herencia, a desidentificarnos de esa matriz colonial. No obstante ello, Pedro Pablo Gómez y Walter Mignolo, en su catálogo de la exposición Estéticas decoloniales (2012) describen claramente esta encrucijada en la que se encuentran las comunidades que han sido presa de la colonialidad,

La emergencia de las estéticas decoloniales, junto a la decolonización del saber, el ser y la misma naturaleza, ha sido y sigue siendo cultivada por comunidades, grupos e individuos que, al ser puestos en condición colonial, han sido subordinados, "racializados", invisibilizados, y negados de múltiples maneras, en cada una de las dimensiones de la matriz moderno/colonial del poder. ${ }^{10}$

He ahí la dificultad para desligarse de esta matriz, pues esa matriz colonial sigue produciendo subjetividades, no solo por la presencia de la colonialidad de poder y sus formas de dominación y explotación, por la colonialidad epistémica y el rol de las epistemologías, y por la colonialidad del saber y sus formas de producción y reproducción del conocimiento, sino que también por la experiencia vivida. Esta experiencia vivida, que nos remite a la obra Franz Fanon, surge a través de la colonización en un primer momento y la posterior colonialidad y su impacto en el lenguaje, que deriva en la constitución de subjetividades, hecho que da lugar a la especificidad de otra colonialidad, la colonialidad del SER que teorizara Nelson Maldonado Torres. ${ }^{11}$ Como ya hemos mencionado, esta es una de las más difíciles de desarticular para deshacernos o desidentificarnos de este legado residual colonial para crear unas nuevas matrices. Tal

\footnotetext{
${ }^{7}$ CÉSAIRE 2006 [1987]: 87.

${ }^{8}$ Como lo denomina el filósofo Samir Amin en: CéSAIRE 2006 [1987]: 95.

9 Dussel 1977.

${ }^{10}$ Gómez, Mignolo 2012: 17-18.

${ }^{11}$ Maldonando-Torres 2007: 127-167.
} 
y como sostiene el sociólogo portugués Boaventura de Sousa Santos en Descolonizar el saber, reinventar el poder,

La identificación de las condiciones epistemológicas permite mostrar la vastísima destrucción de conocimiento propio de los pueblos causada por el colonialismo europeo -lo que llamo epistemicidio-y, por otro lado, el hecho de que el fin del colonialismo político no significó el fin del colonialismo en las mentalidades y subjetividades, en la cultura y en la epistemología y que por el contrario continuó reproduciéndose de modo endógeno. ${ }^{12}$

Esta reproducción endógena de ciertas epistemologías, realizada de manera inconsciente o automática, conduce a la colonialidad del saber. De hecho, más adelante en el texto el autor agrega,

[...] el proceso político tiene necesariamente un horizonte más amplio porque sus resultados no son independientes de derechos y más aún de derechos colectivos que incorporan transformaciones políticas, culturales, de mentalidades y de subjetividades. ${ }^{13}$

Por lo tanto, desde este punto de vista, para alcanzar un cambio se debería arremeter desde diferentes ámbitos de la cultura. En efecto, el Día nacional de los y las afrodescendientes ${ }^{14}$ instaurado recientemente en Argentina (en el año 2013) promueve, desde el ámbito político, un paso más hacia un giro social que venía iniciándose desde hace tiempo, tres o cuatro décadas atrás- que pone en evidencia la necesidad de realizar un reajuste histórico, político, visual y estético al respecto.

A pesar de iniciativas como esta, al investigar sobre el estado de las prácticas artísticas visuales contemporáneas en Argentina en cuanto a la presencia e (in)visibilización de la negritud, lo percibimos con desencanto. A priori, detectamos muy poca evidencia de la presencia de los afrodescendientes, tanto en artistas como en contenidos, en lo que se considera la escena del arte actual. Sólo encontramos su presencia en la cultura popular, sobre todo en la música (tango, milonga, candombe, carnaval y música folklórica) y en las danzas populares (con matriz afro), así como en algunos audiovisuales y cortometrajes sobre este tema. Entre estos últimos destacamos el documental de Milena Annecchiarico, Los argentinos también descendemos de esos barcos,,$^{15}$ en el cual se realiza una reflexión sobre el olvido de las raíces africanas que forman parte de la

12 De Sousa Santos 2010: 7-8.

13 De Sousa Santos 2010: 13-14.

${ }^{14}$ El 24 de abril de 2013 se aprobó en el Senado argentino el proyecto de ley que instituye al 8 de noviembre como el "Día Nacional de las/los Afroargentinas/os y de la Cultura Afro". LEY 26.8522013.

15 Puede visionarse en: ANNECCHIARICO 2013. 
identidad argentina. También artistas plásticas afrodescendientes como Mirta Beatriz Toledo o María Gabriela Pérez, que a propósito del movimiento activista y de la celebración de Día de los y las afrodescendientes han realizado obras y exposiciones sobre la recuperación histórica de celebridades (referentes de la lucha patriótica por la independencia, referentes políticos destacados, etc.) con ascendencia africana. También existe en la actualidad un programa de radio y algunas publicaciones al respecto. ${ }^{16}$

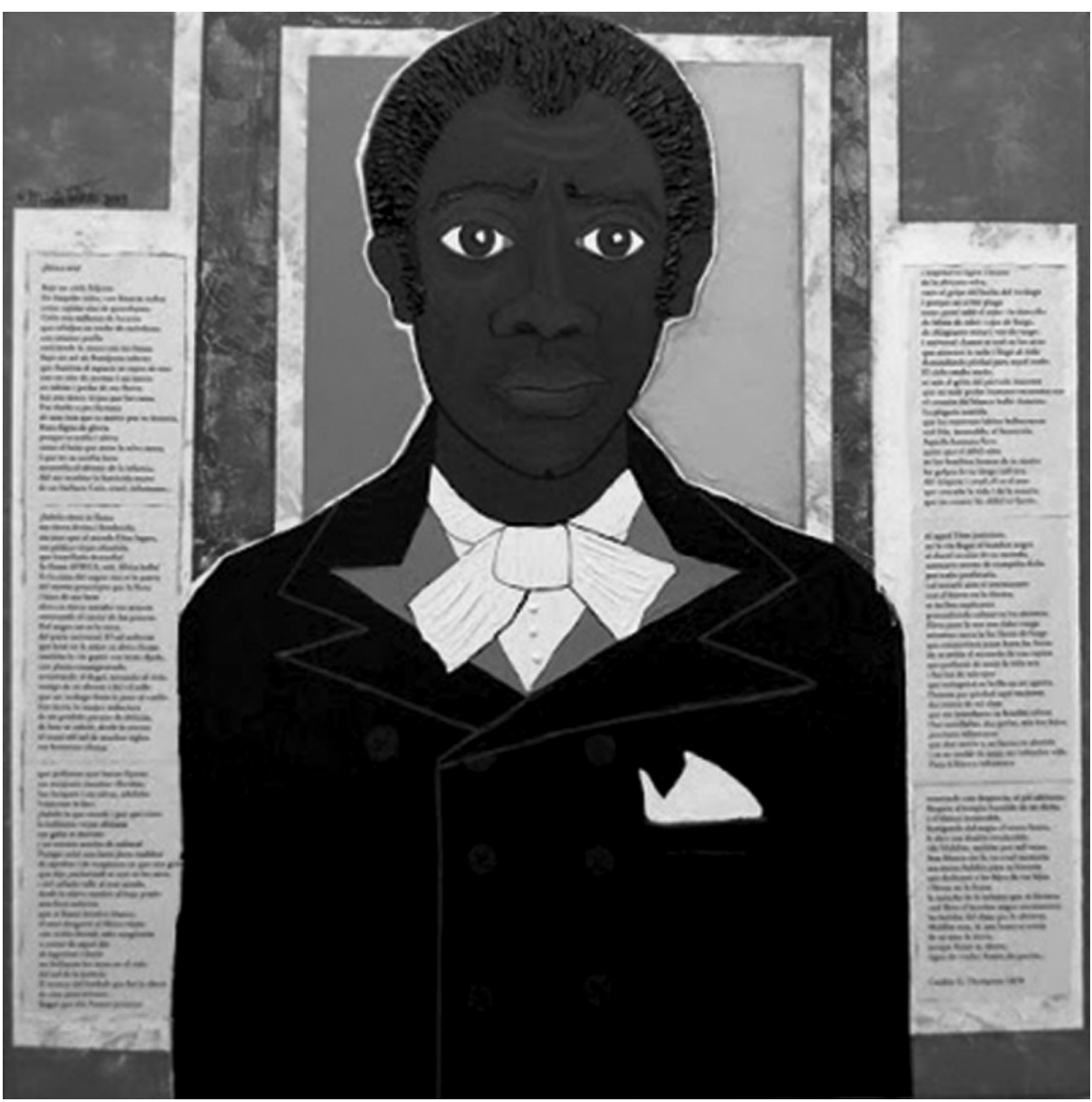

[Fig. 3. Mirta Beatriz Toledo, Casildo Gervasio Thompson, 2013.]

16 También puede consultarse el catálogo de la exposición Antepasados, los Afroporteños en la cultura nacional realizada del mes de mayo a junio de 2016 en el Museo del libro y la lengua de Buenos Aires. Antepasados 2016. 
Como podemos deducir a partir de lo relatado hasta aquí, solo encontramos algunas manifestaciones visuales de la negritud argentina ancestral y presente en forma de acciones de memoria o de recuperación de la memoria que, si bien son necesarias, no son suficientes. En el arte contemporáneo más actual, la huella negra deja bastante que desear, lo cual nos lleva a preguntarnos si esto estará relacionado con la aún elitista o clasista escena / sistema del arte. O si será que la colonialidad epistémica y del saber aún ejerce su poder profundo en las clases más cultivadas.

Podemos elaborar algunos bosquejos o apuntes para posibles respuestas. La descripción fanoniana en Piel negra, máscaras blancas ${ }^{17}$ y en Los condenados de la tierra ${ }^{18}$ de la experiencia vivida por la persona negra, su continua cosificación y erotización que se dio en el Caribe, no funciona de igual manera en Argentina. Más bien, la experiencia parece haber sido la desaparición, la negación e invisibilización de tal experiencia, pues perdura la creencia de que "el negro argentino no existe". Esta huella ha quedado relegada solamente a ciertas formas del campo semántico del habla popular porteño y argentino en referirse a las clases trabajadoras y bajas. Por ejemplo, encontramos expresiones tales como "los negros villeros" para referirse a las personas que viven en las villas miseria o asentamientos informales en el conurbano de las grandes ciudades, o "la negrada / la peonada" a las cuadrillas de peones u obreros, "negro de mierda o de alma" en tanto insulto, o "negrito / negrita" para llamar cariñosamente a alguien familiar. Como podemos apreciar, es como si se tratase de una especie de obliteración del ser negro en pos de un proyecto moderno, blanco y europeizado del estado-nación argentino, lo cual da cuenta de la colonialidad de la memoria y del lenguaje a la que hace referencia Santiago Castro-Gómez.

Por otra parte, Boaventura de Sousa Santos describe esta violencia de la no-representación como "sociología de las ausencias", dice:

Por sociología de las ausencias entiendo la investigación que tiene como objetivo mostrar que lo que no existe es, de hecho, activamente producido como no existente, o sea, como una alternativa no creíble a lo que existe. [...] La no existencia es producida siempre que una cierta entidad es descalificada y considerada invisible, no inteligible o desechable. No hay por eso una sola manera de producir ausencia, sino varias. Lo que las une es una misma racionalidad monocultural. ${ }^{19}$

\footnotetext{
17 FANON 1973 [1952].

18 FANON 1963 [1961].

19 De Sousa Santos 2010: 22.
} 
En este caso podríamos decir que dicha racionalidad que sustenta la ausencia de visibilidad de la negritud no es solo monocultural, sino también racista. Efectivamente, Boaventura de Sousa Santos afirma que,

[...] esta lógica deriva de la monocultura del saber y del rigor del saber, siendo el modo de producción de no existencia más poderoso que consiste en la transformación de la ciencia moderna y de la alta cultura en criterios únicos de verdad y de calidad estética, respectivamente. La complicidad que une las 'dos culturas' reside en el hecho de que se arrogan, en sus respectivos campos, ser cánones exclusivos de producción de conocimiento o de creación artística. Todo lo que el canon no legitima o reconoce es declarado inexistente. La no existencia asume para el autor [o el artista] la forma de ignorancia o de incultura. ${ }^{20}$

La no existencia no asume solo la forma de ignorancia o incultura, sino que podemos añadir la de invisibilidad cultural y, por ende, en la cultura visual. Aunque, como hemos visto, lo declarado no existente -en este caso la negritud- presenta vestigios en el lenguaje popular. Por otra parte, el hecho de que este mito se haya transformado en creencia lo vuelve más áspero a la hora de quebrar sus cimientos. De Sousa Santos hace una distinción entre idea y creencia, la cual "descansa en el hecho de que las creencias son una parte integral de nuestra identidad y subjetividad, mientras que las ideas son exteriores a nosotros". ${ }^{21}$ Por lo tanto,

La dificultad de imaginar la alternativa al colonialismo reside en que el colonialismo interno no es solo ni principalmente una política de Estado, [como sucedía durante el colonialismo de ocupación extranjera]; es una gramática social muy vasta que atraviesa la sociabilidad, el espacio público y el espacio privado, la cultura, las mentalidades y las subjetividades. Es, en resumen, un modo de vivir y convivir muchas veces compartido por quienes se benefician de él y por los que lo sufren. ${ }^{22}$

A modo de conclusión, podemos afirmar que sería necesario emplear todos los ámbitos sociales posibles para la construcción de matrices diversas, de un nuevo léxico, de unas nuevas gramáticas, de una visualidad y de unas nuevas estéticas que deriven en una ecología de saberes y seres que nos permitan divisar desde nuestros propios horizontes los diferentes barcos y sus cargas.

20 De Sousa Santos 2010: 22.

21 De Sousa Santos 2010: 51.

22 De Sousa Santos 2010: 14-15. 


\section{BibliografíA}

AnnecChiarico 2013 - M. Annecchiarico, Los Argentinos También Descendemos de Esos Barcos, 2013, cortometraje documental, 20', Producción: Lúdico Films, Buenos Aires 2013, https://www.youtube.com/ watch? $\mathrm{v}=4$ POrdVHfUfc.

Afrodescendientes 2010 - Argentina Afrodescendientes. Datos del Cuestionario Censal: Afrodescendientes y Multiculturalismo según el Censo de Argentina 2010, en: Instituto Afrodescendiente para el Estudio, la Investigación y el Desarrollo, San José, http://www.afrodesc.com/argentina-afrodescendientes.

Antepasados 2016 - Antepasados, los Afroporteños en la cultura nacional (cat. exp.), Buenos Aires 2016.

Castro-Gómez, Grosfoguel 2007 - S. Castro-Gómez, R. Grosfoguel (eds.), El giro decolonial: reflexiones para una diversidad epistémica más allá del capitalismo global, Bogotá 2007.

CÉSAIRE 2006 [1987] - A. Césaire, Discurso sobre la negritud. Negritud, etnicidad y culturas afroamericanas, en: A. Césaire, Discurso sobre el colonialismo, trad. B. Baltza Álvarez, Madrid 2006, pp. 85-91 [Discours sur la négritude, 1987]

De Sousa Santos 2010 - B. de Sousa Santos, Descolonizar el saber, reinventar el poder, Montevideo 2010.

Dussel 1977 - E. Dussel, Filosofía de la liberación, México 1977.

FANON 1963 [1961] - F. Fanon, Los condenados de la Tierra, trad. J. Campos, México 1963. [Les Damnés de la Terre, 1961]

FANON 1973 [1952] - F. Fanon, Piel negra, máscaras blancas, trad. Á. Abad, Buenos Aires 1973. [Peau noire, masques blancs, 1952]

FoRD 1899 [1878] - J. M. Ford, Beneméritos de mi estirpe. Esbozos sociales al doctor Joaquín Castellanos, La Plata 1899. [1878]

Gómez, Mignolo 2012 - P. P. Gómez, W. Mignolo, Estéticas decoloniales, Bogotá 2012, https://adelajusic.files.wordpress.com/2012/10/decolonial-aesthetics.pdf.

LEY 26.852 2013 - Ley 26.852 "Día Nacional de las/los Afroargentinas/os y de la Cultura Afro" del 24 de abril de 2013, http://servicios.infoleg.gob. ar/infolegInternet/anexos/210000-214999/214825/norma.htm

Maldonado-Torres 2007 - N. Maldonado-Torres, Sobre la decolonialidad del ser: contribuciones al desarrollo de un concepto, en: S. Castro-Gómez, R. Grosfoguel (eds.), El giro decolonial. Reflexiones para 
una diversidad epistémica más allá del capitalismo global, Bogotá 2007, pp.127-167.

Picotтi 2000 - D. V. Picotti, El negro en Argentina. Presencia y negación, "CUYO. Anuario de Filosofía Argentina y Americana", n.17, 2000, pp. 287-296, http://bdigital.uncu.edu.ar/objetos_digitales/1056/picotticuyo17.pdf.

Picotti 2001 - D. V. Picotti (comp.), El negro en Argentina. Presencia y negación, Buenos Aires 2001.

QuiJano 1991 - A. Quijano, Colonialidad y Modernidad/Racionalidad, "Perú Indígena", v.13, n.29, 1991, pp. 11-20.

\section{Summary}

"Argentinians descend from ships", but... from which ones? Notes on the (in)visibilisation of River Plate negritude in the contemporary artistic practices

If epistemic or knowledge colonization is the most difficult to displace from our subjectivities, one can understand that in Latin America -one of those "others close to the West"- a western thinking system still dominates, as being residual from the past colonization. This thinking, heir to European modernist reductionism, entails in itself a fundamental basis: racism -as the poet and politician Aimé Césaire stated in his Discourse on Negritude (1987) and other theoreticians picked up later on. If dominant Euroccidentalism begins with modernity in the midst of Latin America colonisation- and then continues with its humanist school, the persistence of its influence as the prevailing system of thinking should not be surprising, notwithstanding the practical and intellectual efforts made to counteract it for decades.

In the young Argentine Republic of the nineteenth century there was a clear political will to spread the idea of whitening and Europeanization. In fact, social imaginary had been formed, according to which there were no more "black" Argentinians, and this had only been an (extinguished) episode of the Spanish colony. From the hegemonic discourse of power, from education and intellectuality in general, black and autochthonous roots (of native peoples) were denied, with the exception of few patriotic folklorisms. Thus, the collective imaginary would say that the supposed "national identity" was composed of a "melting pot of races", coming mostly from the great European migration. Realizing this, a Mexican writer ironically stated that "while Mexicans descend from the Aztecs, Argentinians descend from ships", echoing a common phrase that expresses an ingrained mythology, especially in Buenos Aires. Jorge Luis Borges would add to this that "Argentines are foreign-born Europeans", shielding the myth against the idea that slave ships from Africa would also land in the port of Buenos Aires 
and that Africans and their descendants would leave their mark on the amalgam of Argentinian national identity. In recent years, however, a social turn seems to emerge calling for a historic and political adjustment in this regard.

In this context, this paper proposes to investigate and reflect on the state of contemporary visual artistic practices regarding the presence and (in)visibilization of negritude, embarking in a brief tour of the fading of black representation in Argentinian visual culture. Despite the little evidence of Afro-descendants' presence both in the overall visual culture and in the aesthetic scenario, negritude is anyway manifested in popular culture, in some audio-visuals and short films or in exhibitions distant from the contemporary art scene, where class perspectives seem to be added to those of race, intrinsic to the art system, through the (in)visibilization of negritude in these latitudes.

\section{Streszczenie}

„Argentyńczycy pochodza ze statków", ale... z których? Uwagi na temat (nie)widoczności „,négritude" regionu rzeki La Platy we współczesnych działaniach artystycznych

Jeśli kolonizację wiedzy lub epistemologii najtrudniej jest usunąć z naszych podmiotowości, to można zrozumieć, że w Ameryce Łacińskiej - jednym z tych „innych bliskich Zachodowi” - zachodni system myślenia wciąż dominuje jako pozostałość po dawnej kolonizacji. Sposób myślenia będący dziedzictwem europejskiego redukcjonizmu modernistycznego wiąże się z podstawową podstawą: rasizmem - zgodnie z tym, co stwierdził poeta i polityk Aimé Césaire w swojej rozprawie „Negritude” (1987) i co podchwycili późniejsi teoretycy. Jeśli dominujący eurookcydentalizm zaczyna się w okresie nowożytności, trwa w okresie kolonizacji Ameryki Łacińskiej, a następnie jest kontynuowany w szkole humanistycznej, to jego nieustający wpływ jako dominującego systemu myślenia nie powinien być zaskakujący mimo wieloletnich praktycznych i intelektualnych wysiłków podejmowanych w celu przeciwdziałania mu.

W młodej dziewiętnastowiecznej Republice Argentyńskiej istniała wyraźna wola polityczna, by szerzyć ideę ,wybielania” i europeizacji. W rzeczywistości kreowano społeczną wyobraźnię, w której nie istnieli „,zarni” Argentyńczycy, stanowiący jedynie (miniony) epizod hiszpańskiej kolonizacji. Z hegemonicznego dyskursu władzy, z systemu edukacji i ludzkiej umysłowości usunięto czarne i autochtoniczne korzenie (rdzennej ludności), z wyjątkiem kilku patriotycznych folkloryzmów. Dlatego w zbiorowej wyobraźni rzekoma „tożsamość narodowa" wywodziła się z ,tygla ras" pochodzącego głównie z wielkiej migracji europejskiej. Zdając sobie z tego sprawę, meksykański pisarz ironicznie stwierdzil, że „podczas gdy Meksykanie pochodzą od Azteków, Argentyńczycy pochodzą ze statków”, odwołując się do popularnego twierdzenia wyrażającego 
mit panujący zwłaszcza w Buenos Aires. Jorge Luis Borges dodaje, że „Argentyńczycy to urodzeni za granicą Europejczycy", i w ten sposób chroni mit przed ideą, że statki z niewolnikami z Afryki dopłynęły również do portu w Buenos Aires i że Afrykańczycy i ich potomkowie także zostawili swój ślad w mieszance tworzącej argentyńską tożsamość narodową. Wydaje się jednak, że w ostatnich latach nastąpiła społeczna zmiana, która zmusza do historycznej i politycznej korekty tej kwestii.

W tym kontekście niniejszy artykuł proponuje omówienie i refleksję nad stanem współczesnych wizualnych działań artystycznych dotyczących obecności i (nie)widoczności „négritude”. Tekst rozpoczyna się od krótkiej dyskusji na temat znikania czarnoskórych artystów z argentyńskiej kultury wizualnej. Pomimo nielicznych dowodów na obecność potomków Afrykańczyków zarówno w ogólnej kulturze wizualnej, jak i w scenariuszu estetycznym „,negritude” mimo to przejawia się w kulturze popularnej, w niektórych materiałach audiowizualnych i krótkich filmach lub wystawach dalekich od współczesnej sceny artystycznej, w których do perspektywy rasowej, nieodłącznie związanej z systemem sztuki, dodana została perspektywa klasowa, przez (nie)widoczność „negritude” na tej szerokości geograficznej. 